\title{
Parental Perception of Word Acquisition and Loss in Autism: A Comparative Study
}

\author{
Bárbara Backes ${ }^{1}$ \\ Tatiana Pontrelli Mecca² (iD \\ Maria Cristina Triguero Veloz Teixeira ${ }^{3}$ \\ Juliana Burges Sbicigo ${ }^{1}$ \\ Cleonice Alves Bosa ${ }^{1}$
}

\begin{abstract}
Some children with Autism Spectrum Disorder (ASD) experience the loss of previously acquired abilities, especially that of using words, a phenomenon that is still poorly understood. This study aimed to investigate parents' perceptions of the age of word acquisition and word loss in individuals with ASD as compared to children with Down Syndrome (DS) and those with typical development (CG). Parents of 77 individuals with ASD, 33 with DS, and 63 from CG completed an inventory on the loss of words and developmental abilities. The median age of acquisition of the first words was 14 months for the ASD group, approximately 4 months after those in CG, and 23 months for the SD group. Word loss occurred only in the ASD group (36.4\%). The median age of loss was 18 months. Parents' perception of word loss can contribute to the understanding of this phenomenon as a potential early ASD indicator.
\end{abstract}

Keywords: Autism, regression, language

\section{Percepção Parental sobre Aquisição e Perda de Palavras no Autismo: Estudo Comparativo}

\begin{abstract}
Resumo: Algumas crianças com Transtorno do Espectro Autista (TEA) apresentam perda de habilidades previamente adquiridas, especialmente a de utilização de palavras, fenômeno ainda pouco compreendido. O objetivo deste estudo foi investigar a percepção dos pais sobre a idade de aquisição e perda de palavras em indivíduos com TEA, comparados a crianças com Síndrome de Down (SD) e desenvolvimento típico (GC). Pais de 77 indivíduos com TEA, de $33 \mathrm{com}$ SD e 63 do GC preencheram um inventário sobre perda de palavras e habilidades de desenvolvimento. A mediana da idade de aquisição das primeiras palavras foi 14 meses no TEA, em torno de quatro meses após o GC, e 23 meses no grupo SD. A perda de palavras ocorreu apenas no grupo TEA (36,4\%). A mediana da idade da perda foi 18 meses. A percepção dos pais sobre a perda de palavras pode contribuir para o entendimento desse fenômeno como um potencial indicador precoce do TEA.
\end{abstract}

Palavras-chave: Autismo, regressão, linguagem

\section{Percepción de los Padres de la Adquisición y Pérdida de Palabras en el Autismo: Un Estudio Comparativo}

Resumen: Algunos niños con trastorno del espectro autista (TEA) experimentan la pérdida de habilidades previamente adquiridas, especialmente palabras, un fenómeno que aún no se comprende bien. El objetivo de este estudio fue investigar la percepción de los padres sobre laedad de adquisición y la perdida de las primeras palabras em indivíduos con TEA, Síndrome de Down (SD) y grupo control típico (GC). Padres de 77 individuos con TEA, 33 com SD y 63 del GC respondieron un inventario de pérdida de vocabulario y habilidades de desarrollo. La mediana de edad de adquisición de las primeras palabras fue 14 meses em el TEA, alrededor de 4 meses más tarde que el GC, y 23 meses en el grupo SD. La pérdida de vocabulário fue observada solamente em el grupo TEA $(36,4 \%)$. En este grupo la mediana de edad de ocurrencia de la pérdida fue 18 meses. La percepción de los padres de la pérdida de vocabulário puede contribuir a la comprensión de este fenómeno como un potencial indicador precoz del TEA.

Palabras clave: Autismo, regresión, lenguaje

\footnotetext{
${ }^{1}$ Universidade Federal do Rio Grande do Sul, Porto Alegre-RS, Brazil

${ }^{2}$ Faculdade de Ciências Médicas da Santa Casa de São Paulo, São Paulo-SP, Brazil

${ }^{3}$ Universidade Presbiteriana Mackenzie, São Paulo-SP, Brazil

Article originated from the first author's doctoral dissertation under supervision by the fifth author, defended in 2016, in the Graduate Program in Psychology at Universidade Federal do Rio Grande do Sul. Support: The study was funded by the Coordenação de Aperfeiçoamento de Pessoal de Nível Superior (CAPES)

Correspondence address: Cleonice Alves Bosa. Universidade Federal do Rio Grande do Sul. Rua Ramiro Barcelos, 2600, Porto Alegre-RS, Brasil. CEP 90.040-060. E-mail: cleonicebosa@gmail.com
}

Autism Spectrum Disorder (ASD) compromises social interaction and communication with significant impairments in adaptive functioning (Maenner et al., 2020). Although the socio-communicative deficit is a common element, the symptomatology, severity levels, and developmental trajectory do not necessarily follow the same pattern in all children (Lord, Bishop, \& Anderson, 2015; Masi, DeMayo, Glozier, \& Guastella, 2017). 
The onset of symptoms can occur by: the early onset in the first year of life; regressive onset (symptoms appear after a period of apparently typical development and are preceded by ability loss); a combination of previous patterns; a stagnation pattern (typical onset of social and language abilities) without subsequent gains (Boterberg, Charman, Marschik, Bolte, \& Roeyers, 2019). These different aspects have been studied as forms of the early onset of ASD signals (Parmeggiani, Corinaldesi, \& Posar, 2019). Specifically, regression and loss of previously acquired abilities are exclusively ASD manifestations, yet it is not a sign shown by all children who have the disorder (Thurm, Powell, Neul, Wagner, \& Zwaigenbaum, 2018). Its variability is still a subject of investigation. The etiology and significance of this phenomenon are not clearly established (Pearson, Charman, Happé, Bolton, \& McEwen, 2018). This study addressed the regressive onset of the disorder, also referred to as "Developmental Regression" (DR), specifically for the loss of the communicative use of three or more words (except 'dad' and 'mom') for at least three months.

DR is an essential clinical criterion of Childhood Disintegrative Disorder; however, unlike that disorder, in which the loss is global in almost all developmental milestones, in ASD, the loss or regression in vocabulary is a typical warning sign of the disorder (Mehra et al., 2019; Ozonoff \& Iosif, 2019). Lord, Shulman, and Dilavore (2004) evaluated 112 children for word loss at ages 2, 3, 4, and 5 and observed that this sign is an ASD-specific phenomenon, allowing for greater reliability in its identification. There is a higher prevalence of word loss in this group compared to other conditions (Thurm, Manwaring, Luckenbaugh, Lord, \& Swedo, 2014). Word loss in the second year of life may be a risk sign for ASD, although it is not a universal phenomenon for the disorder (Backes, Zanon, \& Bosa, 2017; Parmeggiani et al., 2019).

Word loss occurs, on average, at 21.36 months (Barger, Campbell, \& McDonough, 2013) and affects approximately $20 \%$ to $32 \%$ of children with ASD (Boterberg, Charman, et al., 2019). Language changes are part of the clinical condition of other neurodevelopmental, disorders, such as intellectual disability and language disorder (Hyman, Levy, Myers, \& Council on Children with Disabilities, Section on Developmental and Behavioral Pediatrics, 2020). Hence, word loss has been investigated to determine whether the phenomenon is typical of ASD or shared with other disorders. However, when compared to children with intellectual disability associated with genetic syndromes, for example Down Syndrome (DS), children with language disorder or typical development do not manifest this pattern of vocabulary loss (Thurm et al., 2014). Castillo et al. (2008) investigated the age of word loss onset in children with DS and comorbidity with ASD compared to children with ASD, showing that language regression occurred in the group with DS and ASD, but at later developmental ages compared to children with ASD without DS. The evidence indicates that this characteristic is a potential early indicator of ASD (Boterberg, Charman, et al., 2019), and may be one of the first warning signs identified by parents around 30 months (Barger et al., 2013; Zanon, Backes, \& Bosa, 2014).

There are three general categories regarding communication losses in ASD: fluctuating word loss, vocalization loss, and word loss (Lord et al., 2004), the latter being the most important and associated with the loss of other abilities, such as social interest and playing (Barger et al., 2013). This association can be clarified by the assumptions of the sociopragmatic perspective, which considers that the emergence of linguistic symbols (e.g., words) and their social use are only possible after the establishment of socio-cognitive abilities, such as shared attention, understanding of communicative intention, and imitation with role reversal (Tomasello, 2003). There seems to be a trajectory that starts with dyadic and extends to triadic interaction in shared attention scenes, in which the use of gestures is an essential indicator of socio-cognitive development (Ramos-Cabo, Vulchanov, \& Vulchanova, 2019). In the socio-pragmatic perspective, intersubjective and perspectival processes are established in these interactions and culminate in the emergence of symbolic play and words (Tomasello, 2003). Such processes are found to be deficient in ASD (Hyman et al., 2020). However, there is still insufficient evidence of the association of altered communication and social interaction in ASD with DR, specifically with word loss. The hypothesis is that the occurrence of word loss is more frequent in the ASD group as compared to children with intellectual disability or language disorders (Hyman et al., 2020).

This study aimed to investigate parents' perception of the age of word acquisition and loss in individuals with autism spectrum disorder (ASD), compared to children with Down Syndrome (DS) and typical development (CG). Also investigated in the ASD group was the association between showing word loss and the presence of socio-cognitive abilities. It is important to investigate this phenomenon in other cultures, since the literature review showed that the topic tends to be more studied in English-speaking countries. Moreover, it is relevant to investigate the phenomenon based on parents' reports, since the information brought by them during the evaluation processes is of fundamental importance to establish clinical reasoning regarding the history of signs and symptoms.

Additionally, we investigated the number of words, word classes and the communicative purpose before the loss and how much of these abilities had been recovered by the time of evaluation. Finally, the ASD group was subdivided into individuals with and without word loss so as to investigate the association between this characteristic and others related to social-cognitive development.

\section{Method}

\section{Participants}

This is a retrospective, cross-sectional, comparative study. Initially, 87 parents of children with ASD (autistic spectrum disorder) and 47 with DS (Down Syndrome) participated to 
control variables "delay in global development" and "language development", as well as 74 parents of children from CG (typical development), comprising individuals with no reported delay in vocabulary acquisition or global development. The inclusion criterion was a previous medical diagnosis of ASD or DS.

Participants with uncorrected sensory impairments and showing signs of delayed acquisition of the first words and phrases (acquisition of the first words after 14 months and the first phrases after 25 months) were excluded from CG. Such a delay was defined based on language assessment by the Bayley Scale of Infant Development (Bayley, 2006). Children who scored from 7 to 23 points on M-CHAT or from 3 to 6 points considering the critical items were excluded from the DS and CG groups. Parents and caretakers retrospectively completed M-CHAT (Losapio \& Pondé, 2008) by checking for signs of ASD when children were from 24 to 30 months old. In the ASD group, M-CHAT was applied to track the signs also retrospectively, from 24 to 30 months.

After applying the exclusion criteria, 10 participants with ASD and three with DS were excluded because they had uncorrected sensory impairments. In the DS group, 11 participants were excluded with indications of risk for ASD by M-Chat. In CG, 10 participants were excluded because they showed evidence of language delay, and three participants were excluded because M-CHAT indicated risk for ASD. The final sample consisted of 77 children with ASD, 33 with DS, and 61 in CG.

Table 1 shows the participants' sociodemographic characteristics. The three groups were equivalent regarding maternal education and socioeconomic status, but differed regarding gender. The ASD group had a larger number of boys, which ratifies previous reports in the literature (Maenner et al., 2020), and CG had a larger number of girls. There was a significant association between age and group, with CG consisting of younger children. A significant association was found between group and regular school attendance, with a higher percentage of participants with ASD not attending regular school, followed by the DS group and CG, respectively. Most participants in the three groups resided in the Southern region of Brazil (ASD 49.4\%; DS 36.4\%; CG 92.1\%).

Table 1

Frequency and Percentage of Sociodemographic Characteristics of Participants and Parents by Group

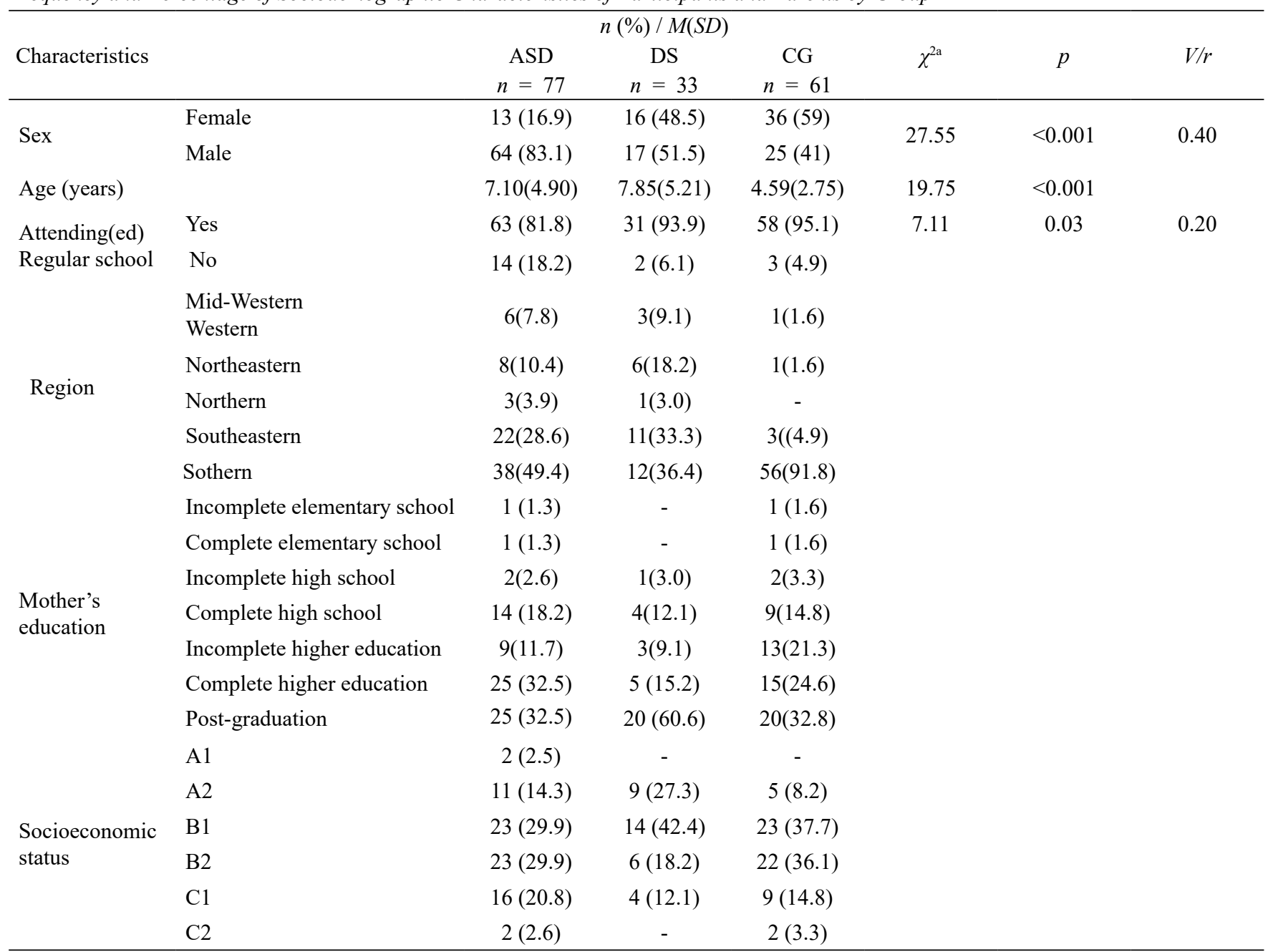

Note. ASD = Autistic Spectrum Disorder; DS = Down Syndrome; CG = Control Group; *The level of significance adopted was $5 \%(p \leq 0.05)$; ${ }^{a}$ Chi-square test for categorical variables or Kruskall-Wallis test for continuous variables. 


\section{Instruments}

Form for children's sociodemographic and linguistic milestone acquisition data (FSD). It was designed for this study to characterize the participants regarding the acquisition of the main linguistic milestones, among other aspects described in Tables 1 and 2.

Socioeconomic Questionnaire of the Brazilian Association of Survey Companies (ABEP, 2009). Instrument used to classify the participants' socioeconomic status.

$M$-CHAT. An ASD screening instrument translated by Losapio and Pondé (2008). It consists of 23 items that investigate social interaction, communication, makebelieve play, and social referencing (Cronbach's alpha = 0.85 for the complete checklist and 0.83 for the critical items). It was used retrospectively in the case of older children, with caregivers responding according to the child's behavior shown at 24 months.

Bayley-III Scale of Infant Development (Bayley, 2006). An individually administered scale that assesses five major development domains in children from 1 to 42 months of age. The domains assessed are cognition, language (receptive and expressive communication), motor (gross and fine), socialemotional, and adaptive behavior. There is validity evidence for the scale scores in a domestic study (Madaschi, Mecca, Macedo, \& Paula, 2016).

Inventory of loss of words and other abilities (ILW) (developed for this study). It assesses the acquisition and subsequent loss of words and abilities in other developmental areas. Part 1 consists of 12 items that investigate the characteristics associated with word loss and aims to examine the word classes used by children before and after the loss (nouns, adjectives, and verbs), their quantity, communicative purpose (declarative or imperative function, naming), among other aspects; part 2 investigates the occurrence of ability loss in other developmental areas (e.g. social interaction, play). This part consists of two items and 13 sub-items that investigate the type of abilities lost, the age at the loss onset and duration, and whether it was sudden or gradual.

\section{Procedures}

Data collection. This was a mixed collection (online and onsite) since the data were collected in different regions of the country. Participants were contacted through institutions for people with ASD, schools, family associations, and social media. The Survey Monkey ${ }^{\circledR}$ platform was used for the online collection, resulting in a total of 140 participants ( $\mathrm{ASD}=75, \mathrm{DS}=33$ and $\mathrm{CG}=32$ ). On-site collection took place in public and private schools in the southern region, totaling 31 participants $(\mathrm{ASD}=2, \mathrm{DS}=0$ and $\mathrm{CG}=29$ ).

Data analysis. Non-parametric statistics was used due to the non-normal distribution. Frequencies $(f \%)$, means $(M)$, standard deviations $(S D)$, medians $(M d)$, and first and third quartiles $(Q 1-Q 3)$ were calculated. The Kruskal-Wallis test with Dunn's post hoc, adjusted with Bonferroni correction, was used to compare linguistic milestone acquisition and loss between groups. Associations between variables were investigated using the chi-square test. Effect sizes were reported ( $\mathrm{r}$ for Dunn's post hoc comparisons; Cramer's V for chi-square) following Cohen's (1988) interpretation. The significance level adopted was 5\%.

\section{Ethical Considerations}

The participants signed an Informed Consent Form. The study was approved by the Research Ethics Committee of the Instituto de Psicologia da Universidade Federal do Rio Grande do Sul (CAAE no. 27403214000005334, with Report no. 623765), in accordance with Resolution no. 466, dated December 12, 2012.

\section{Results}

The ages of acquisition of the first linguistic milestones differed between the groups (Table 2). The ASD and DS groups showed later acquisition of the first vocalizations, words, and phrases as compared to GC. There were no significant differences between the ASD and DS groups. The magnitude of the differences ranged from moderate to strong.

Table 2

Differences Between Groups at the Age (in Months) of Language Milestone Acquisition

\begin{tabular}{|c|c|c|c|c|c|c|c|c|c|c|c|c|c|c|}
\hline & \multicolumn{2}{|c|}{ ASD } & \multicolumn{4}{|c|}{$\mathrm{DS}$} & \multicolumn{2}{|c|}{ CG } & \multirow[b]{2}{*}{$\begin{array}{c}M d \\
(Q 1-Q 3)\end{array}$} & \multirow[b]{2}{*}{$\chi^{2}$} & \multicolumn{3}{|c|}{$p$} & \multirow[t]{2}{*}{$r$} \\
\hline & $n$ & $\begin{array}{c}M \\
(S D)\end{array}$ & $\begin{array}{c}M d \\
(Q 1-Q 3)\end{array}$ & $n$ & $\begin{array}{c}M \\
(S D)\end{array}$ & $\begin{array}{c}M d \\
(Q 1-Q 3)\end{array}$ & $N$ & $\begin{array}{c}M \\
(S D)\end{array}$ & & & $\begin{array}{l}\operatorname{ASD} x \\
D S(Z)^{\mathrm{a}}\end{array}$ & $\begin{array}{l}\text { ASD x } \\
C G(Z)^{\mathrm{a}}\end{array}$ & $\begin{array}{c}S D \mathrm{x} \\
C G(Z)^{\mathrm{a}}\end{array}$ & \\
\hline $\begin{array}{l}\text { The first } \\
\text { vocalizations }\end{array}$ & 69 & $\begin{array}{l}9.26 \\
(9.35)\end{array}$ & $\begin{array}{c}6 \\
(5-12)\end{array}$ & 30 & $\begin{array}{c}9.10 \\
(7.85)\end{array}$ & $\begin{array}{c}7 \\
(5-12)\end{array}$ & 58 & $\begin{array}{c}4.72 \\
(2.51)\end{array}$ & $\begin{array}{c}4 \\
(3-6)\end{array}$ & 22.09 & 1.69 & 35.59 & 33.90 & $\begin{array}{l}0,39^{\mathrm{b}} / \\
0,36^{\mathrm{c}}\end{array}$ \\
\hline $\begin{array}{l}\text { The first } \\
\text { words }\end{array}$ & 68 & $\begin{array}{c}20.37 \\
(15.10)\end{array}$ & $\begin{array}{c}14 \\
(14-24)\end{array}$ & 33 & $\begin{array}{c}24.00 \\
(15.45)\end{array}$ & $\begin{array}{c}23 \\
(14-27)\end{array}$ & 61 & $\begin{array}{l}10.49 \\
(2.36)\end{array}$ & $\begin{array}{c}11 \\
(9-12)\end{array}$ & 41.69 & 23.65 & 37.57 & 61.23 & $\begin{array}{l}0,40^{\mathrm{b}} / \\
0.62^{\mathrm{c}}\end{array}$ \\
\hline $\begin{array}{l}\text { The first } \\
\text { phrases }\end{array}$ & 42 & $\begin{array}{c}43.10 \\
(19.78)\end{array}$ & $\begin{array}{c}43 \\
(29-49)\end{array}$ & 21 & $\begin{array}{c}35.38 \\
(18.44)\end{array}$ & $\begin{array}{c}30 \\
(24-36)\end{array}$ & 59 & $\begin{array}{l}16.25 \\
(4.50)\end{array}$ & $\begin{array}{c}15 \\
(12-19)\end{array}$ & 71.89 & 10.41 & 57.16 & 46,75 & $\begin{array}{l}0,80^{\mathrm{b} /} \\
0,58^{\mathrm{c}}\end{array}$ \\
\hline
\end{tabular}

Note. ASD = Autistic Spectrum Disorder; DS = Down Syndrome; CG = Control Group; $M d=$ Median; Q1-Q3 = first and third quartiles; ${ }^{\mathrm{a}}$ Dunn's post hoc Test; ${ }^{\mathrm{b} E f f e c t ~ s i z e ~ o f ~ t h e ~ p o s t ~ h o c ~ d i f f e r e n c e s ~ b e t w e e n ~ A S D ~ x ~ C G ; ~ ' ~}{ }^{\mathrm{E} f f e c t}$ size of the post hoc differences between DS x CG; Numbers in bold point to significant differences $(p<0.001 ; p<0.005)$. 
Word loss was more frequent in the ASD group (28 participants, $36.4 \%$ ) as compared to DS (0\%) and CG $(0 \%), \chi^{2}(2)=40.88 ; p<.001$. A new analysis regarding the mean age of acquisition of the first words was performed, but considering the ASD group without loss $(n=49)$, ASD with loss $(n=28)$, DS $(n=33)$, and CG $(n=61)$. Significant differences were found between the groups, $\chi^{2}=50.54 ; p<0.01, r=0.53$. Post hoc comparisons indicated that the ASD group with loss ( $M d=12$ months) acquired words earlier than participants in the ASD group without loss ( $M d=18$ months), $Z=34.36 ; p<0.001$, and than participants in the DS group ( $M d=23$ months), $Z=44.37 ; p<0.001$. CG ( $M d=11$ months) acquired words earlier than the ASD group without loss ( $M d=18$ months), $Z=51.22 ; p<0.001$, and than the DS group, $Z=61.23 ; p<0.001$.

The mean age of word loss onset was 20.61 months ( $M d=18$ months) in the group of 28 participants with ASD (SD $=8$ months), and it was sudden for $53.6 \%$ of cases and gradual for $46.4 \%$. Furthermore, in the parents' perception, 78.6\% $(n=22)$ reported not relating word loss to any events, including health and family problems or stressors; $10.7 \%(n=3)$ related it to health problems (i.e., the child's hospitalization), and $10.7 \%(n=3)$ associated the loss with other factors, such as reactions to vaccination.

Figure 1 shows that of the 28 participants with ASD who had word loss, $57.1 \%(n=16)$ spoke from five to 10 words before the loss, and 25\% $(n=7)$ spoke from 11 to 20 words. Participants who spoke fewer than 20 words accounted for approximately $17.9 \%$. As for word classes, $100 \%$ of the individuals with ASD who lost words used nouns (Figure 1), and as regards communicative purposes, $71.4 \%(n=20)$ used words to make requests (Figure 1).

Of the 28 participants with ASD with word loss, $35.7 \%$ $(n=10)$ had not recovered lost words by the time of the study; $35.7 \%(n=10)$ recovered some words, and $28.6 \%$ $(n=8)$ recovered all lost words. As for loss duration, the mean time was 22.9 months $(S D=19.1)$.

BEFORE WORD LOSS $(n=28)$

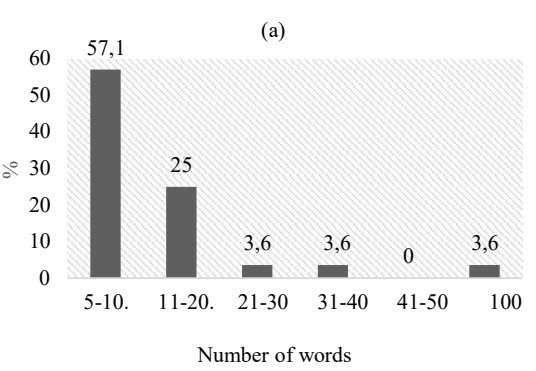

(d)

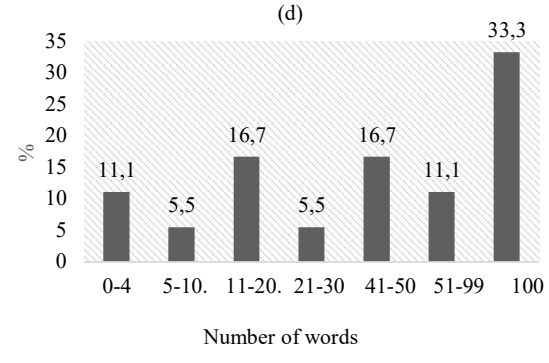

(b)

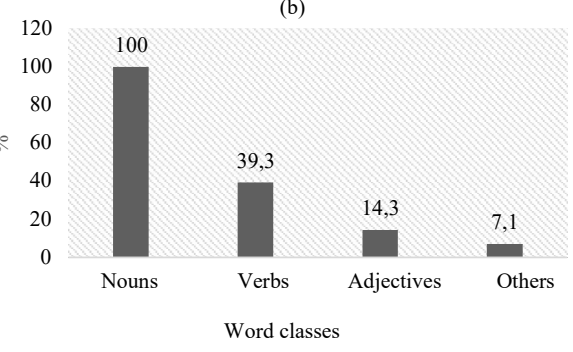

WORD RECOVERY $(n=18)$

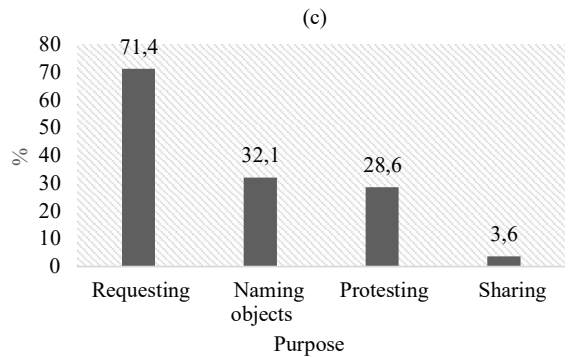

Purpose

(e)

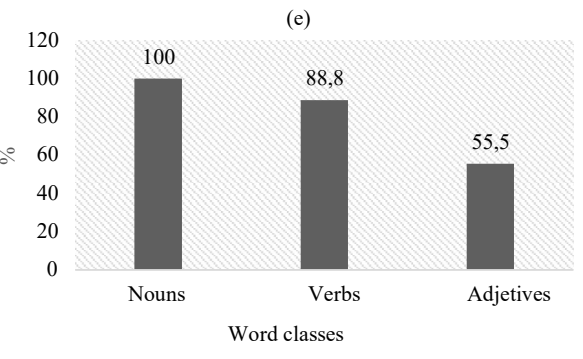

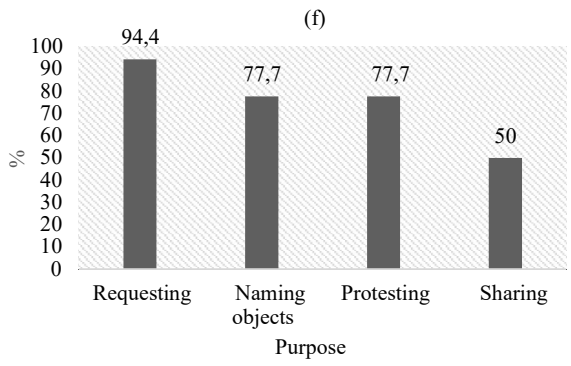

Figure 1. Number of words, word classes, and purpose before word loss and at word recovery.

Of the 18 participants who recovered some or all of the lost words at the time of this study, 33.3\% $(n=6)$ spoke more than 100 words (Figure 1). Regarding the word classes used by such participants, it was found that $100 \%(n=18)$ spoke nouns (Figure 1). With regard to the communicative purposes, $94.4 \%(n=17)$ of the participants used words to make requests (Figure 1).

In Table 3, it is observed that, in the group with ASD and with word loss $(n=28)$, the median age of loss of the ability to smile at other people was 16 months, whereas for the abilities to keep eye contact during communication, to respond when called by one's name, and the intention to communicate, it was 18 months. The abilities to eat by oneself and to use gestures, and interest in symbolic and interactive play had a median age of loss from 19 to 24 months. Eye contact during communication, the ability to respond when called by one's name, and the interest in interactive play were the most frequently lost abilities $(64.3 \%)$. There was a significant association between word loss and all social and play abilities except for eating by oneself. The magnitude of the association was strong and significant between word loss and responding to being called by one's name $\left(\chi^{2}=10.56 ; p=0.01\right)$, smiling at others $\left(\chi^{2}=8.14 ; p=0.04\right)$, interest in interactive play $\left(\chi^{2}=7.23\right.$; $p=0.01)$, intention to communicate $\left(\chi^{2}=6.52 ; p=0.01\right)$, and use of gestures $\left(\chi^{2}=5.05 ; p=0.02\right)$. 
Table 3

Age of Loss Onset and Association Between Word Loss and Loss of Social Skills and Play in the ASD Group

\begin{tabular}{|c|c|c|c|c|c|c|}
\hline Type of Loss & $\begin{array}{l}\text { Age of Loss Onset } \\
M(S D) ; M d\end{array}$ & $\begin{array}{c}\text { ASD without loss }(n=49) \\
N(f \%)\end{array}$ & $\begin{array}{c}\text { ASD with loss }(n=28) \\
N(f \%)\end{array}$ & $\chi^{2}$ & $p$ & $V$ \\
\hline $\begin{array}{l}\text { Use of eye contact during } \\
\text { communication }\end{array}$ & $19.75(7.59) ; 18$ & & & & & \\
\hline No & & $27(55.1)$ & $10(35.7)$ & 2.68 & 0.10 & 0.19 \\
\hline Yes & & $22(44.9)$ & $18(64.3)$ & & & \\
\hline $\begin{array}{l}\text { Ability to respond when called } \\
\text { by one's name }\end{array}$ & 21.23(10.05); 18 & & & & & \\
\hline No & & $36(73.5)$ & $10(35.7)$ & 10.56 & 0.01 & 0.37 \\
\hline Yes & & $13(26.5)$ & $18(64.3)$ & & & \\
\hline Interest in interactive play & $21.92(9.31) ; 23$ & & & & & \\
\hline No & & $33(67.3)$ & $10(35.7)$ & 7.23 & 0.01 & 0.31 \\
\hline Yes & & $16(32.7)$ & $18(64.3)$ & & & \\
\hline Smiling at other people & $17.69(7.29) ; 16$ & & & & & \\
\hline No & & $41(83.7)$ & $15(53.6)$ & 8.14 & 0.04 & 0.33 \\
\hline Yes & & $8(16.3)$ & $13(46.4)$ & & & \\
\hline Intention to communicate & $19.86(7.80) ; 18$ & & & & & \\
\hline No & & $41(83.7)$ & $16(57.1)$ & 6.52 & 0.01 & 0.29 \\
\hline Yes & & $8(16.3)$ & $12(42.9)$ & & & \\
\hline Use of gestures & $29.38(22.37) ; 24$ & & & & & \\
\hline No & & $41(83.7)$ & $17(60.7)$ & 5.05 & 0.02 & 0.26 \\
\hline Yes & & $8(16.3)$ & $11(39.3)$ & & & \\
\hline Interest in symbolic play & $20.29(4.96) ; 24$ & & & & & \\
\hline No & & $30(61.2)$ & $11(39.3)$ & 3.45 & 0.06 & 0.21 \\
\hline Yes & & $19(38.8)$ & $17(60.7)$ & & & \\
\hline Ability to eat by oneself & $21.25(11.24) ; 19$ & & & & & \\
\hline No & & $39(79.6)$ & $20(71.4)$ & 0.66 & 0.41 & 0.09 \\
\hline Yes & & $10(20.4)$ & $8(28.6)$ & & & \\
\hline
\end{tabular}

Note. Data not available for all participants showing loss; therefore, the number of cases corresponding to the presented mean is reported; $* 5 \%$ significance level adopted.

\section{Discussion}

The main objective in this study was to investigate the acquisition and loss of first words in individuals with ASD, compared to children with DS and children with typical development (CG). As expected, word loss was significantly more frequent in the ASD group as compared to the other conditions. Studies with comparative designs have shown that word loss is significantly more frequent in ASD than in other groups with intellectual disabilities (Thurm et al., 2018), a result also found in this study. Therefore, language loss may be a potential early indicator of ASD (Barger et al., 2013; Zanon et al., 2014), whose main characteristic is the occurrence of near-typical development before the loss, followed by the appearance of ASD signs (Boterberg, Charman, et al., 2019).

The prevalence of word loss in the group with ASD (36.4\%), and the combined prevalence of word loss with social ability loss (33.7\%) are similar to those previously reported (Barger et al., 2013; Thurm et al., 2018). The variation in loss rates is due to different factors, such as the method for participant selection and the type of ability investigated (Barger et al., 2013). The mean prevalence found in this study was $32.1 \%$; the prevalence for language regression was $24.9 \%$, and the prevalence for language regression and social abilities combined was $38.1 \%$. A previous study involving a parental survey reported $40.8 \%$ (Barger et al., 2013). Lord et al. (2004) also reported similar percentages to those in the present study, indicating $38.23 \%$ of children with losses in communication abilities.

Regarding the age of word loss onset in ASD, the mean found was 23.25 months, corroborating previous findings (Barger et al., 2013), but differing from Lord et al. (2004), who reported a mean of 16.2 months for the onset of word loss, indicating the heterogeneity of this phenomenon in ASD (Boterberg, Charman, et al., 2019). According to the report by some parents, the loss of some social abilities showed an earlier onset mean than that of word loss (e.g., loss of eye contact during communication, loss of smiling at others. However, most of them perceived that word loss occurred before losses in other abilities. Word loss is often the first cause for parental concern because it characterizes an apparent developmental disruption, making it a more easily identifiable loss. The heterogeneity of this clinical manifestation has been predominantly studied based on parental reporting (Williams, Brignell, Prior, Bartak, \& Roberts, 2015). 
Thurm et al. (2018) report three patterns for the onset of ASD signs: early onset (before 12 months), developmental stagnation (e.g., in early language abilities), and loss of abilities in one or more domains, with language being one of the main domains affected. These signs may also show for other types of losses in social interaction and adaptive functioning abilities.

Zanon et al. (2014) showed that the focus of parental concern about the nature of the first ASD signs tends to be related to delayed speech, revealing that oral language is an area of development that attracts attention from families. The loss of social abilities (social smiling, eye contact), on the other hand, may be subtle initially and not immediately identifiable. Although parents may identify the losses and DR in their children at different times during development, these losses are related, according to the assumptions of the socio-pragmatic theory by Tomasello (2003).

We also observed an association between word loss and the loss of social and play abilities, such as the use of gestures, eye contact and social smiling, the ability to respond when called by one's name, and interest in interactive play, thus corroborating other studies (Thurm et al., 2014). Basing on socio-pragmatic assumptions, it is consistent to state that children with ASD and a history of word loss possess, prior to the occurrence of this phenomenon, at least the basic socio-cognitive and socio-interactionist competencies necessary for the emergence of the linguistic symbol (Tomasello, 2003). Otherwise, the emergence of communicative word use would not be feasible.

The associations found between DR (word loss) indicators and abilities in the socio-cognitive domain of the ASD group indicate that health professionals should be attentive to different changes in expected developmental milestones that together may signal an alert for ASD. Parents' and caregivers' reports, in combination with observations and the use of standardized instruments, are essential for decision-making before and after the regression phenomenon (Thurm et al., 2018).

Furthermore, according to Tomasello's theories, the developmental course that leads to the emergence of the linguistic symbol necessarily goes through the use of social abilities. Initially this occurs in non-verbal communicative contexts, and also in combination with verbal communicative channels later. Thus, it is plausible to assume, based on the postulations of the socio-pragmatic perspective, that the disruption in some part of this process, such as word loss, is accompanied by disruptions or losses regarding social interaction and play abilities. In this study, however, no association was found between word loss and symbolic play loss, which can be explained by the fact that the latter was in the early stages of development when word loss occurred. Thus, because it is an ability still rudimentarily used by the child at the time of the loss (around 24 months or less), it is plausible to state that the identification of the loss by the parents is a complex and inaccurate task.

In this study, the mean word loss duration was 22.9 months. In this regard, $35.7 \%$ of the participants with ASD and a history of word loss did not recover the lost words, and that partially or completely occurred to the remaining participants. It is known that not all children with ASD and an RD history recover the lost abilities. When such recovery does occur, to some degree, the process tends to be slow and not always linear (Stefanatos, 2008). Although controversial, some studies show that this phenomenon negatively influences the prognosis in ASD (Boterberg, Charman, et al., 2019).

Regarding the age of acquisition of the first words, CG differed from the other two groups (ASD and DS) by having acquired the first words at the end of the first year of life. These results are not surprising, since one of the characteristics of ASD and DS are alterations in language development (Ramos-Cabo et al., 2019). Moreover, it is also interesting to note the differences in acquisition time from one stage to another (from vocalization to words, and from words to phrases). In CG, evolutions occurred every six months, still in the first year of life, while in the clinical groups, such time was doubled.

Another result is that the ASD group acquired their first words earlier than the DS group. It should be noted that $36.4 \%$ of the children with ASD had word loss, that is, they had already acquired this milestone at an expected age, as reported by their parents. Regarding the age of acquisition of the first words, it was observed that the group with ASD showing word loss differed from the group with DS and the group with ASD without word loss. The age of acquisition was similar to that of CG. This milestone was acquired, on average, at the expected age in the ASD and word loss group, according to previous findings (Thurm et al., 2018).

This study also investigated the quantity, classes, and communicative purpose of the words used by individuals with ASD before and after word loss. Regarding the number of words, most participants spoke from five to 10 words before the loss. Considering that the mean age at the loss onset was 23.25 months, this quantity may suggest that the acquisition was already compromised, even before the loss. These data agree with previous literature reports on the presence of sometimes subtle delays prior to the loss occurrence (Boterberg, Van Coster, \& Roeyers, 2019; Ozonoff \& Iosif, 2019). Regarding the word classes utilized before the loss, all individuals used nouns to communicate, followed by verbs, corroborating Brazilian research on lexical acquisition (Nóro, Silva, Wiethan, \& Mota, 2015). These authors investigated children from 12 to 23 months old, an age that would represent the period before the loss for the sample in this study, and during the entire period studied, nouns were significantly more frequent than verbs, although the occurrence of the latter qualitatively and gradually increased. Initial lexical acquisition tends to include words related to the context in which the child is communicatively engaged, and this is a complex process that depends on the child's ability to categorize. Thus, the frequent occurrence of nouns in children's lexicon can be explained by the fact that they are more concrete referents, with less complex symbolic connotation as compared to other word classes. This can also be observed in relation to the acquisition of verbs, which tends 
to initially involve actions related to concrete clues, such as the verb "to eat", which can be represented by a gesture. Later, generic verbs are acquired, which can denote different actions (e.g., to do) and lack gestural cues (Nóro et al., 2015).

The results in this study also showed that the words were used to ask, to name, or to protest. Indeed, the communicative function becomes complex throughout the course of development. Initially, children tend to use words with an imperative purpose (e.g., request) to later use declarative functions (e.g., sharing). This is because, in agreement with what happens in the acquisition of word classes, children first use words according to the interactive scenes that they experience to communicate needs and desires, that is, with an imperative function. As the child's linguistic and cognitive repertoire expands, he/she starts to enter into more complex scenes, involving a purely social purpose, using words to share interests, that is, with a declarative function (Tomasello, 2003). The number of words used by individuals at the time of the present study (after the loss had occurred) varied, which may be related to the different developmental trajectories achieved by individuals with ASD (Ramos-Cabo et al., 2019). The analysis of word classes and communicative purposes of the words used by the individuals after the loss showed the same logic observed before the loss. That is, a high frequency of nouns and the imperative function; however, in this second moment, it is possible to observe other word classes that begin to appear in the individuals' vocabulary (e.g., adjectives), as well as declarative communicative purposes.

The investigation on word loss in the ASD group as compared to the other groups showed that, although some aspects are within the expected range for the age before the loss (e.g., age of acquisition of the first words), qualitative changes in language development can already be observed (e.g., quantity of words used before the loss), indicating the presence of even subtle delays before the loss (Boterberg, Van Coster, et al., 2019).

The findings support the hypothesis that word loss may be a warning sign for ASD, as language regression distinguished this group from the others. These data indicate that the patterns of regressive onset of communication abilities occur very frequently in ASD, and can validate a typical phenomenon for this group. This result may have implications for ASD screening, and investigation of word loss in routine assessments by health professionals is recommended. It is noteworthy that even though other alterations may be present before the loss, they seem subtle to be a reason for parental concern at first. Thus, word loss is often the first change noticed by parents, but it is a phenomenon that is still not well known by professionals who work with child development. Therefore, it is essential that knowledge about word loss, including its characteristics, age of occurrence, associated factors, among others, be expanded and disseminated in different fields, given both its diagnostic and interventional importance.

Among the limitations to the study is its cross-sectional rather than longitudinal design, which restricts the possibility of inferring other types of associations between the variables investigated. Moreover, this is a retrospective study based on parents' self-report, so the information is subject to informants' biases, which indicates that, although vocabularyrelated DR was found, caution should be exercised in drawing conclusions based on parents' retrospective reports without direct measurements on children, considering the age range of the sample. Another limitation was the mixed data collection model (onsite and online) because the initial number of participants in the DS and CG groups was small.

Due to the non-probability sampling, the generalization of findings should be considered with caution. On the other hand, convenience sampling enabled a wider range of families residing in different regions of the country, thus broadening the scope of the study. The concentration of respondents in economic classes A and B, with high-school to college education, indicates that the sample is not representative of the Brazilian population (Brazilian Institute of Geography and Statistics [IBGE], 2010).

It is also pointed out that the operational definition of some items in the instrument used could be more precise, such as the one referring to the age of acquisition of the first phrases and the type of loss (whether gradual or sudden). Although the results were based on parental reporting, they reinforce the importance of parents' and pediatricians' monitoring $\mathrm{RD}$ indicators in children with suspected developmental delays and/or ASD signs; especially because DR is an early clinical marker of the disorder that, when identified, can contribute not only to the accuracy of the ASD diagnosis, but also to the planning of interventions in the domains of language and social communication abilities. Finally, because this was a survey on the acquisition and loss of the first words, the prevalence found may be a little higher than that found in the general population, according to previous findings. Furthermore, the fact that we did not use judges to administer ILW and the use of direct measurements on children from 12 to 14 months of age are considered limitations to the study. Despite these limitations, the results are considered relevant, as they indicate the phenomenon of word loss in a group of individuals with ASD during childhood, corroborating previous literature. Further investigation with a representative sample of the Brazilian population and prioritizing longitudinal, prospective designs that assess the development of children at risk for ASD is suggested in order to better understand this apparent disruption that affects children with DR.

\section{References}

Associação Brasileira de Empresas de Pesquisa. (2009). Critério de classificação econômica Brasil [Brazil economic classification criteria]. Retrieved from http:// www.abep.org/criterio-brasil

Backes, B., Zanon, R. B., \& Bosa, C. A. (2017). Características sintomatológicas de crianças com autismo e regressão da linguagem oral [Symptomatic characteristics of children with autism and language regression]. Psicologia: Teoria e Pesquisa, 33, e3343. doi:10.1590/0102.3772e3343 
Barger, B. D., Campbell, J. M., \& McDonough, J. D. (2013). Prevalence and onset of regression within autism spectrum disorders: A meta-analytic review. Journal of Autism and Developmental Disorders, 43(4), 817-828. doi:10.1007/s10803-012-1621-x

Bayley, N. (2006). Bayley Scales of Infant and Toddler Development (3rd ed.). San Antonio, TX: Harcourt Assessment.

Boterberg, S., Charman, T., Marschik, P. B., Bölte, S., \& Roeyers, H. (2019). Regression in autism spectrum disorder: A critical overview of retrospective findings and recommendations for future research. Neuroscience and Biobehavioral Reviews, 102, 24-55. doi:10.1016/j. neubiorev.2019.03.013

Boterberg, S., Van Coster, R., \& Roeyers, H. (2019). Characteristics, early development and outcome of parentreported regression in autism spectrum disorder. Journal of Autism and Developmental Disorders, 49(11), 46034625. doi:10.1007/s10803-019-04183-X

Castillo, H., Patterson, B., Hickey, F., Kinsman, A., Howard, J. M., Mitchell, T., \& Molloy, C. A. (2008). Difference in age at regression in children with autism with and without Down syndrome. Journal of Developmental \& Behavioral Pediatrics, 29(2), 89-93. doi:10.1097/ DBP.0b013e318165c78d

Cohen, J. (1988). Statistical power analysis for the behavioral sciences (2nd ed.). New York, NY: Psychology Press.

Hyman, S. L., Levy, S. E., Myers, S. M., \& Council on Children with Disabilities, Section on Developmental and Behavioral Pediatrics. (2020). Identification, evaluation, and management of children with autism spectrum disorder. Pediatrics, 145(1), e20193447. doi:10.1542/ peds.2019-3447

Instituto Brasileiro de Geografia e Estatística. (2010). Censo demográfico 2010 [2010 demographic census]. Rio de Janeiro, RJ: Autor. Retrieved from https://censo2010. ibge.gov.br/

Lord, C., Bishop, S., \& Anderson, D. (2015). Developmental trajectories as autism phenotypes. American Journal of Medical Genetics. Part C, Seminars in Medical Genetics, 169(2), 198-208. doi:10.1002/ajmg.c.31440

Lord, C., Shulman, C., \& DiLavore, P. (2004). Regression and word loss in autistic spectrum disorders. Journal of Child Psychology and Psychiatry, and Allied Disciplines, 45(5), 936-955. doi:10.1111/j.1469-7610.2004.t01-1-00287.x

Losapio, M. F., \& Pondé, M. P. (2008). Translation into Portuguese of the M-CHAT Scale for early screening of autism. Revista de Psiquiatria do Rio Grande do Sul, 30(3), 221-229. doi:10.1590/S0101-81082008000400011

Madaschi, V., Mecca, T.P., Macedo,E.C.,\&Paula,C.S.(2016). Bayley-III scales of infant and toddler development: Transcultural adaptation and psychometric properties. Paidéia (Ribeirão Preto), 26(64), 189-197. doi:10.1590/1982-43272664201606
Maenner, M. J., Shaw, K. A., Baio, J., Washington, A., Patrick, M., DiRienzo, M., ... Dietz, P. M. (2020). Prevalence of autism spectrum disorder among children aged 8 years - autism and developmental disabilities monitoring network, 11 sites, United States, 2016. Morbidity and Mortality Weekly Report. Surveillance Summaries, 69(4), 1-12. doi:10.15585/mmwr.ss6904a1

Masi,A., DeMayo, M. M., Glozier, N., \& Guastella,A. J. (2017) An overview of autism spectrum disorder, heterogeneity and treatment options. Neuroscience Bulletin, 33(2), 183-193. doi:10.1007/s12264-017-0100-y

Mehra, C., Sil, A., Hedderly, T., Kyriakopoulos, M., Lim, M., Turnbull, J., ... Absoud, M. (2019). Childhood disintegrative disorder and autism spectrum disorder: A systematic review. Developmental Medicine \& Child Neurology, 61(5), 523-534. doi:10.1111/dmcn.14126

Nóro, L.A., Silva, D. D., Wiethan, F. M., \& Mota, H. B. (2015). Initial lexical acquisition and noun bias hypothesis verification. Revista CEFAC, 17(Suppl. 1), 52-59. doi:10.1590/1982-0216201517s14613

Ozonoff, S., \& Iosif,A. M. (2019). Changing conceptualizations of regression: What prospective studies reveal about the onset of autism spectrum disorder. Neuroscience \& Biobehavioral Reviews, 100, 296-304. doi:10.1016/ j.neubiorev.2019.03.012

Parmeggiani, A., Corinaldesi, A., \& Posar, A. (2019). Early features of autism spectrum disorder: A crosssectional study. Italian Journal of Pediatrics, 45(1), 144. doi:10.1186/s13052-019-0733-8

Pearson, N., Charman, T., Happé, F., Bolton, P. F., \& McEwen, F. S. (2018). Regression in autism spectrum disorder: Reconciling findings from retrospective and prospective research. Autism Research, 11(12), 16021620. doi:10.1002/aur.2035

Ramos-Cabo, S., Vulchanov, V., \& Vulchanova, M. (2019). Gesture and language trajectories in early development: An overview from the autism spectrum disorder perspective. Frontiers in Psychology, 10, 1211. doi:10.3389/fpsyg.2019.01211

Stefanatos, G. A. (2008). Regression in autistic spectrum disorders. Neuropsychology Review, 18(4), 305-319. doi:10.1007/s11065-008-9073-y

Thurm, A., Manwaring, S. S., Luckenbaugh, D. A., Lord, C., $\&$ Swedo, S. E. (2014). Patterns of early skill attainment and loss in young children with autism. Development and Psychopathology, 26(1), 203-214. doi:10.1017/ S0954579413000874

Thurm, A., Powell, E. M., Neul, J. L., Wagner, A., \& Zwaigenbaum, L. (2018). Loss of skills and onset patterns in neurodevelopmental disorders: Understanding the neurobiological mechanisms. Autism Research, 11(2), 212-222. doi:10.1002/aur.1903

Tomasello, M. (2003). The cultural origins of human cognition. Cambridge, MA: Harvard University Press. 
Williams, K., Brignell, A., Prior, M., Bartak, L., \& Roberts, J. (2015). Regression in autism spectrum disorders. Journal of Paediatrics and Child Health, 51(1), 61-64. doi:10.1111/jpc. 12805

Zanon, R. B., Backes, B., \& Bosa, C. A. (2014). Identificação dos primeiros sintomas do autismo pelos pais [Parents' perception of the first symptoms of autism]. Psicologia: Teoria e Pesquisa, 30(1), 25-33. doi:10.1590/S010237722014000100004

Bárbara Backes is a volunteer researcher at Universidade Federal do Rio Grande do Sul, Porto Alegre-RS, Brazil.

Tatiana Pontrelli Mecca is a Professor at Faculdade de Ciências Médicas da Santa Casa de São Paulo, São PauloSP, Brazil.

Maria Cristina Triguero Veloz Teixeira is a Professor in the Graduate Program in Developmental Disorders at Universidade Presbiteriana Mackenzie, São Paulo-SP, Brazil.

Juliana Burges Sbicigo is a volunteer researcher at Universidade Federal do Rio Grande do Sul, Porto AlegreRS, Brazil.

Cleonice Alves Bosa is a Professor in the Graduate Program in Developmental and Personality Psychology at Universidade Federal do Rio Grande do Sul, Porto Alegre-RS, Brazil.

\section{Authors' Contribution:}

All authors made substantial contributions to the conception and design of this study, to data analysis and interpretation as well as to the manuscript revision and approval of the final version. All the authors assume public responsibility for the manuscript content.

Associate editor:

Vanessa Barbosa Romera Leme

Received: Aug. 14, 2020

1st Revision: Dec. 01, 2020

2nd Revision: Dec. 16, 2020

Approved: Jan. 04, 2021

How to cite this article:

Backes, B., Mecca, T. P., Teixeira, M. C. T. V., Sbicigo, J. B., \& Bosa, C. A. (2021). Parental perception of word acquisition and loss in autism: A comparative study. Paidéia (Ribeirão Preto), 31, e3116.doi:https://doi.org/10.1590/1982-4327e3116 